\title{
Uncertainties in Flexural Strength of Carbon/Glass Fibre Reinforced Hybrid Epoxy Composites
}

\author{
Chensong Dong* \\ Department of Mechanical Engineering, Curtin University, GPO Box U1987, Perth, Western \\ Australia 6845, Australia
}

\begin{abstract}
A study on the flexural behaviours of the of glass and carbon fibre reinforced epoxy hybrid composites is presented in this paper. Two types of glass fibres: S-2 and E, and two types of carbon fibres: T700S and P-100 are investigated. The flexural strength is obtained using an approach based on finite element analysis. Three compressive strength models: Lo-Chim, Budiansky and the shear models are used to obtain the flexural strengths. It is shown from the results that when shear failure occurs, the flexural strength is $20-30 \%$ lower compared to other failure modes.
\end{abstract}

Keywords: A. Polymer-matrix composites (PMCs); A. Hybrid; B. Strength

\section{Nomenclature}

$\begin{array}{ll}b & \text { Width of the specimen }(\mathrm{mm}) \\ D & \text { Maximum deflection }(\mathrm{mm}) \\ E_{m} & \text { Modulus of the matrix }(\mathrm{GPa}) \\ E_{11} & \text { Longitudinal modulus of composite }(\mathrm{GPa}) \\ e_{h} & \text { Hybrid effect } \\ G_{f 12} & \text { Shear modulus of fibres }(\mathrm{GPa})\end{array}$

\footnotetext{
* Corresponding author. Tel: +61 (8) 92669204; fax: +61 (8) 92662681; email: c.dong@ curtin.edu.au.
} 


\begin{tabular}{|c|c|}
\hline$G_{12}$ & Shear modulus of composite (GPa) \\
\hline$h$ & Depth of the specimen (total thickness of the laminate) (mm) \\
\hline$h_{c}$ & Thickness of the carbon/epoxy section (mm) \\
\hline$h_{g}$ & Thickness of the glass/epoxy section (mm) \\
\hline$P_{\max }$ & The maximum load encountered before failure $(\mathrm{N})$ \\
\hline$r_{h}$ & Hybrid ratio \\
\hline$S$ & Span of the specimen (distance between to supporting pins) (mm) \\
\hline$S_{F}$ & Flexural strength of hybrid composite (MPa) \\
\hline$S_{F c}$ & Flexural strength of carbon/epoxy composite (MPa) \\
\hline$S_{F g}$ & Flexural strength of glass/epoxy composite (MPa) \\
\hline$S_{F R o M}$ & Flexural strength of hybrid composite from the rule of mixtures (MPa) \\
\hline$S_{L C}$ & Longitudinal compressive strength of composite (MPa) \\
\hline$S_{L T}$ & Longitudinal tensile strength of composite (MPa) \\
\hline$S_{L T S}$ & Shear strength of composite (MPa) \\
\hline$S_{m y}$ & Yield strength of the matrix $(\mathrm{MPa})$ \\
\hline$S_{m u}$ & Strength of the matrix (MPa) \\
\hline$S_{S m}$ & Shear strength of the matrix $(\mathrm{MPa})$ \\
\hline$V_{f c}$ & Fibre volume fraction of the carbon/epoxy section \\
\hline$V_{f g}$ & Fibre volume fraction of the glass/epoxy section \\
\hline$x, y, z$ & Coordinates $(\mathrm{mm})$ \\
\hline$\varepsilon_{f u}$ & Strain of fibres \\
\hline$\varepsilon_{m y}$ & Yield strain of the matrix \\
\hline
\end{tabular}



Ultimate strain of the matrix

\section{Introduction}

Hybrid composites have received great research interest for the capabilities of achieving tailored material properties. One common hybrid composite is made by reinforcing a common matrix by carbon and glass fibres. Although carbon fibres are well known for high strength, they have low strain-to-failure because of their high stiffness. Compared to carbon fibres, glass fibres have much higher strain-to-failure due to their lower modulus. From this point, it is possible to increase the strain-to-failure by substitution of carbon fibres for glass fibres.

The mechanical properties of a hybrid composite is often simply obtained by using a general rule of mixtures (RoM) approach, which quantifies a material property with respect to the volume concentration of its constituents. However, research shows that hybrid effects exist, i.e. the material property as predicted by the RoM differs from that observed in reality [1-11]. A positive deviation of a certain mechanical property from the RoM prediction is called positive hybrid effect, and vice versa [12]. In addition to hybrid composites reinforced by carbon and glass fibres, hybrid composites reinforced by other fibre types e.g. carbon and basalt [13], kenaf and glass [14], banana and sisal [15], and jute and banana [16] are also studied.

Dong et al. $[2,3,6,7]$ studied the flexural properties of unidirectional carbon/glass fibre reinforced hybrid epoxy composites using both experiments and finite element analysis (FEA). It is shown partial substitution of carbon fibres for glass fibres on the compressive side results in improved flexural strength, i.e. positive hybrid effect. Dong et al. $[1,4,5]$ further investigated optimal design of hybrid composites. It is concluded that in order to achieve positive hybrid effects, the fibre volume fraction of the glass/epoxy section needs to be higher than that of the carbon/epoxy section 
$[1,4]$. In our previous study, it is also shown that large variations in the flexural properties exist in carbon/glass fibre reinforced epoxy hybrid composites [2]. This study aims at providing an explanation of the variations in the flexural properties. For this purpose, two types of glass fibres: S-2 and E, and two types of carbon fibres: T700S and P-100 are chosen, and the flexural properties of glass and carbon fibre reinforced epoxy hybrid composites are obtained with the aid of FEA.

\section{Flexural PropertiesStrength Modelling}

\subsection{Material Properties}

In this study, two types of glass fibres: S-2 (high strength) and E (low electrical conductivity), and two types of carbon fibres: T700S (high strength) and P-100 (high modulus) are chosen. The hybrid composites are made by embedding one type of carbon fibres and one type of glass fibres into one common matrix, epoxy. The typical material properties of the fibres and matrix are shown in Table 1. The lamina properties, including the longitudinal modulus $E_{11}$, the transverse moduli $E_{22}$ and $E_{33}$, and the shear moduli $G_{12}, G_{13}$ and $G_{23}$, are derived from the constituent properties using Hashin's model [17], and the lamina stiffness matrices are derived.

Table 1: Typical properties of fibres and resin

\begin{tabular}{lccc}
\hline \multicolumn{1}{c}{ Material } & $\begin{array}{c}\text { Tensile modulus } \\
(\mathrm{GPa})\end{array}$ & $\begin{array}{c}\text { Tensile strength } \\
(\mathrm{MPa})\end{array}$ & $\begin{array}{c}\text { Density } \\
\left(\mathrm{kg} / \mathrm{m}^{3}\right)\end{array}$ \\
\hline Carbon fibres (T700S) & 230 & 4900 & 1800 \\
Carbon fibres (P-100) & 758 & 2200 & 1800 \\
S-2 glass fibres & 86.9 & 4890 & 2460 \\
E glass fibres & 72 & 3450 & 2580 \\
Epoxy & 3.1 & 69.6 & 1090 \\
\hline
\end{tabular}

\subsection{Longitudinal Compressive Strength}

It is seen from our previous studies $[2,3,6,7]$ that failure mostly occurs at the compressive side. Thus, the compressive strength needs to be derived. For a laminated composite, the longitudinal 
compressive strength is dependent on the failure mode, and possible compressive failure modes include pure compression, delamination/shear, and microbuckling or kinking.

For the delamination/shear failure mode, the compressive strength is given by [18]:

$$
S_{L C}=10 S_{L T S}+2.5 S_{m u}
$$

where

$$
S_{L T S}=\left\lfloor 1-\left(\sqrt{V_{f}}-V_{f}\right)\left(1-G_{m} / G_{f 12}\right)\right] S_{S m}
$$

For the microbuckling or kinking mode, Lo-Chim model [19] is used to predict the compressive strength of a unidirectional laminate. This model is given by:

$$
S_{L C}=\frac{G_{12}}{1.5+12(6 / \pi)^{2}\left(G_{12} / E_{11}\right)}
$$

Our previous studies $[2,3,6,7]$ showed this was the most common failure mode. Another widely used model was developed by Budiansky and Fleck [20], which is given by:

$$
S_{L C}=\frac{G_{m}}{\left(1-V_{f}\right)\left(1+\phi / \gamma_{Y}\right)}
$$

\subsection{Longitudinal Tensile Strength}

In some uncommon cases, e.g. in which high modulus carbon fibres are used, a specimen under flexural loading may fail on its tensile side. Thus, tensile strengths are also needed for predicting the flexural strength.

In general, fibres exhibit elastic behaviour, but yielding must be taken into account for the matrix. If the fibres have higher failure strain than the matrix, e.g. glass, yield of the matrix needs to be considered. In this study, a bi-linear relationship as shown in Figure 1 is used to describe the stressstrain relationship for the epoxy. 
It is shown from an experimental study [21] that $\varepsilon_{m u}$ is approximately $4 \%$. The yield strength is empirically determined to be $S_{m y} \approx 0.75 S_{m u}$. The yield strain is then $\varepsilon_{m y} \approx 0.75 S_{m u} / E_{m}$. The modulus of the epoxy in the plastic region is then $E_{m p}=0.25 S_{m u} /\left(\varepsilon_{m u}-\varepsilon_{m y}\right)$. If the fibres fail before the ultimate strain of the epoxy, the effective modulus of the epoxy is given by

$$
E_{m e}=\frac{0.75 \varepsilon_{m u}+0.25 \varepsilon_{f u}-\varepsilon_{m y}}{\varepsilon_{f u}\left(\varepsilon_{m u}-\varepsilon_{m y}\right)} S_{m u}
$$

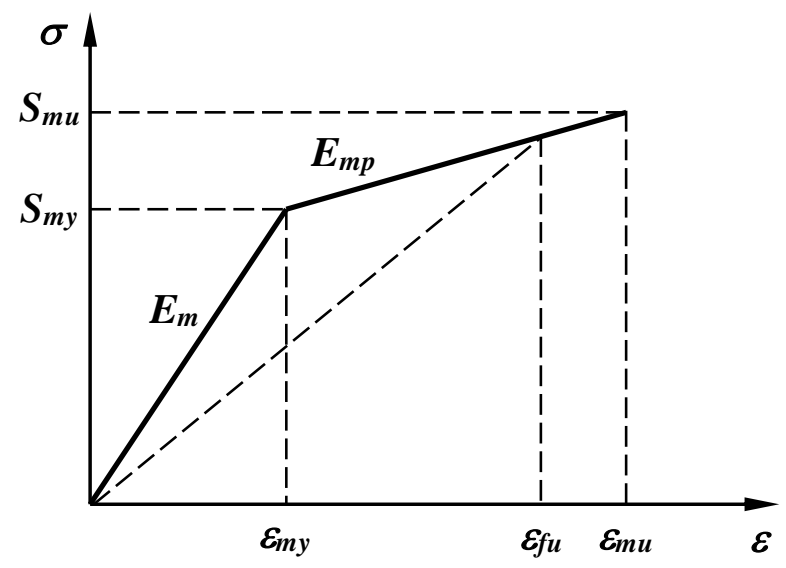

Figure 1: Bi-linear stress-strain relationship for epoxy

If the epoxy fails before the fibres, the effective modulus for the epoxy is then $E_{m e}=S_{m u} / \varepsilon_{m u} . E_{m e}$ can be used in the micromechanical modelling for deriving the lamina properties. The longitudinal tensile strength is given by

$$
S_{L T}=E_{11} \varepsilon_{m u}
$$

On the other hand, if the fibres have lower failure strain than the matrix, e.g. carbon, the possible failure mode is fibre breakage, and the longitudinal strength can be simply calculated using the effective modulus and fibre failure strain, e.g. $1.65 \%$ for T700S graphite fibres, i.e.

$$
S_{L T}=E_{11} \varepsilon_{f u}
$$




\subsection{Comparison of Tensile and Compressive Strengths}

The tensile and compressive strengths of the epoxy composites reinforced by these four types of fibres: T700S, P-100, S-2 and E are shown in Figure 2. It is seen in general, the tensile strength is much higher than the compressive one, which explains why a composite specimen fails in compression under flexural loading. However, for P-100/epoxy composite, when the fibre volume fraction is less than $50 \%$, the tensile strength is lower than the compressive one. This means at low fibre volume fractions, a P-100/epoxy specimen fails in tension under flexural loading.

For carbon fibre reinforced epoxy composites, the compressive strength of shear mode is much lower than those of microbuckling or kinking mode. In consequence, the flexural strength is lower due to shear failure. This has been experimentally shown in our previous study [2].

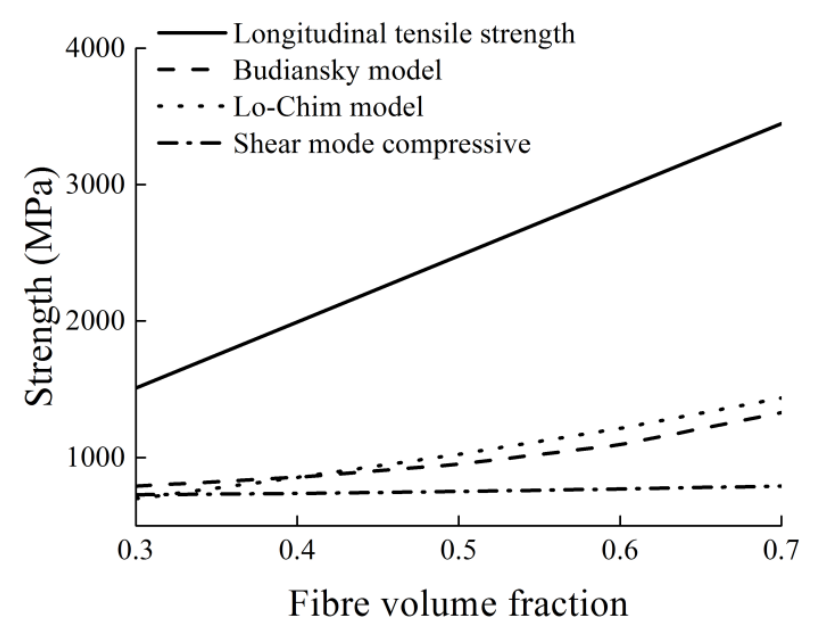

(a)

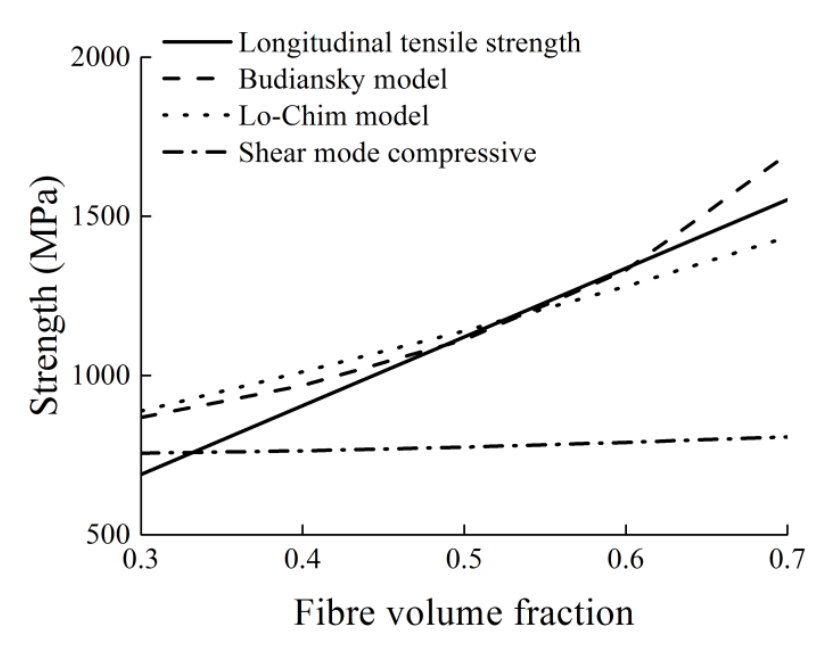

(b) 


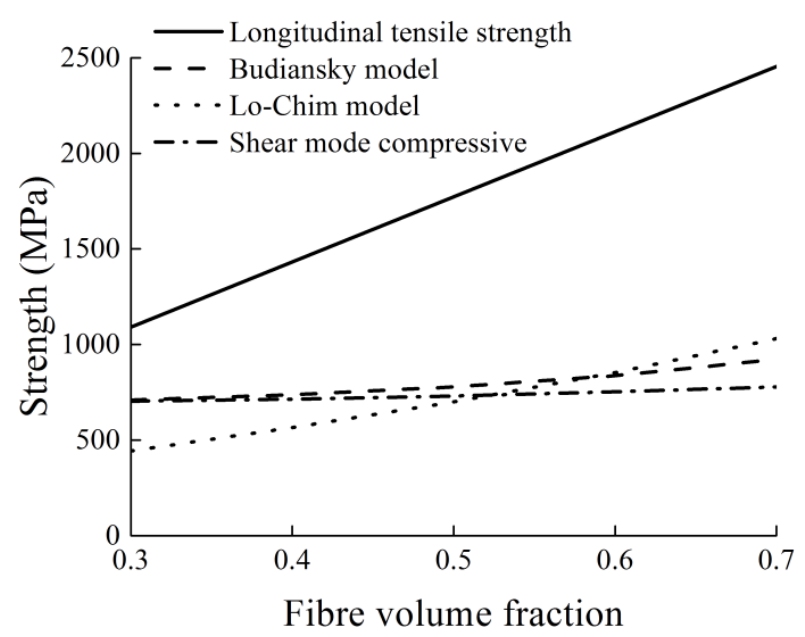

(c)

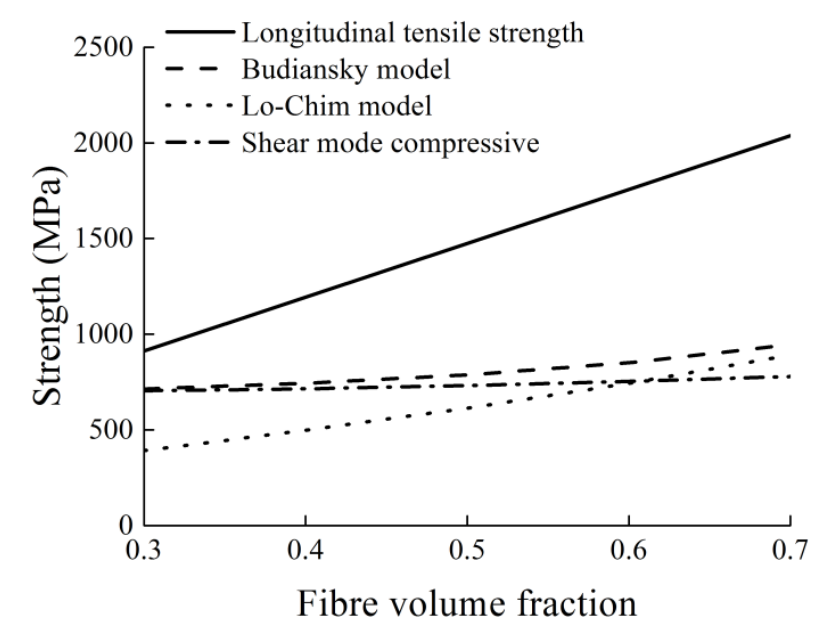

(d)

Figure 2: Strengths of epoxy composites reinforced by four types of fibres: (a) T700S; (b) P-100; (c) S-2; (d) E

When Lo-Chim model is used for the compressive strength, the tensile and compressive strains of the epoxy composites reinforced by these four types of fibres: T700S, P-100, S-2 and E are shown in Figure 3. It is seen that both the tensile and compressive failure strains of glass/epoxy composites are significantly higher than those of carbon/epoxy composites. Because of this, it is possible to extend the strain-to-failure by partially substituting carbon/epoxy composites for glass/epoxy ones.

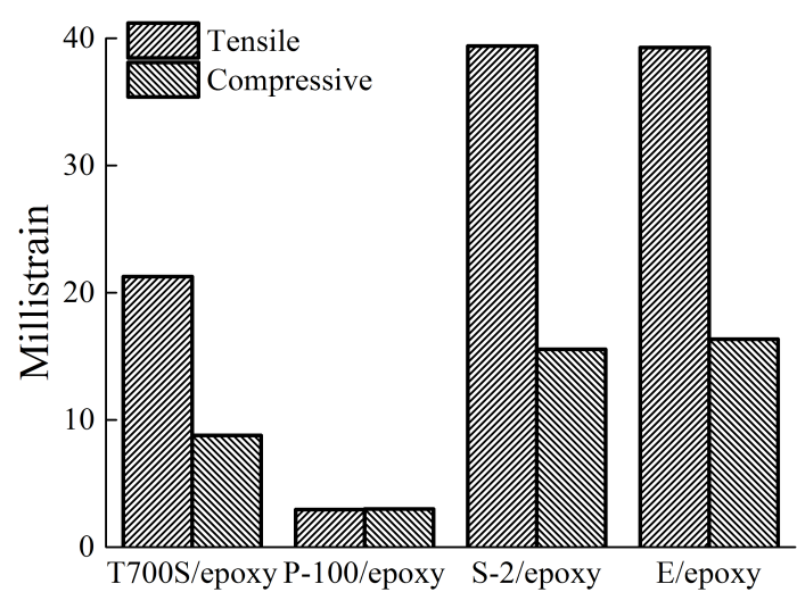

Figure 3: Strains of epoxy composites reinforced by four types of fibres: T700S, P-100, S-2 and E; the fibre volume fractions are $50 \%$ 


\section{Flexural Properties Modelling}

With reference to our previous studies [1-7], the stacking configuration for the hybrid composites is achieved by partially substituting carbon/epoxy laminas on the compressive side of a full carbon/epoxy composite laminate for glass/epoxy laminas. For the purpose of quantitatively characterising the degree of hybridisation, hybrid ratio is introduced, which is the relative percentage of glass fibres with respect to all fibres, i.e.

$$
r_{h}=\frac{h_{g} V_{f g}}{h_{g} V_{f g}+h_{c} V_{f c}}
$$

A hybrid composite specimen under the three point bending is schematically shown in Figure 4 . In this study, the stress and strain under flexural loading are obtained by FEA [6, 7] using ANSYS. An example finite element model is shown in Figure 5. The element type is PLANE182. Half of the specimen is modelled by applying symmetry boundary condition on the left end face (represented by the triangles pointing to the right). On the right edge, the $y$ displacement is constrained (represented by the upward triangle) to simulate the support in three point bending. The bending load is defined by a pressure over a small area to simulate the geometry of the loading nose, and is increased until the maximum stress reaches the corresponding strength. The maximum load is used to calculate the flexural strength and the load-displacement curve is used to calculate the flexural modulus. 


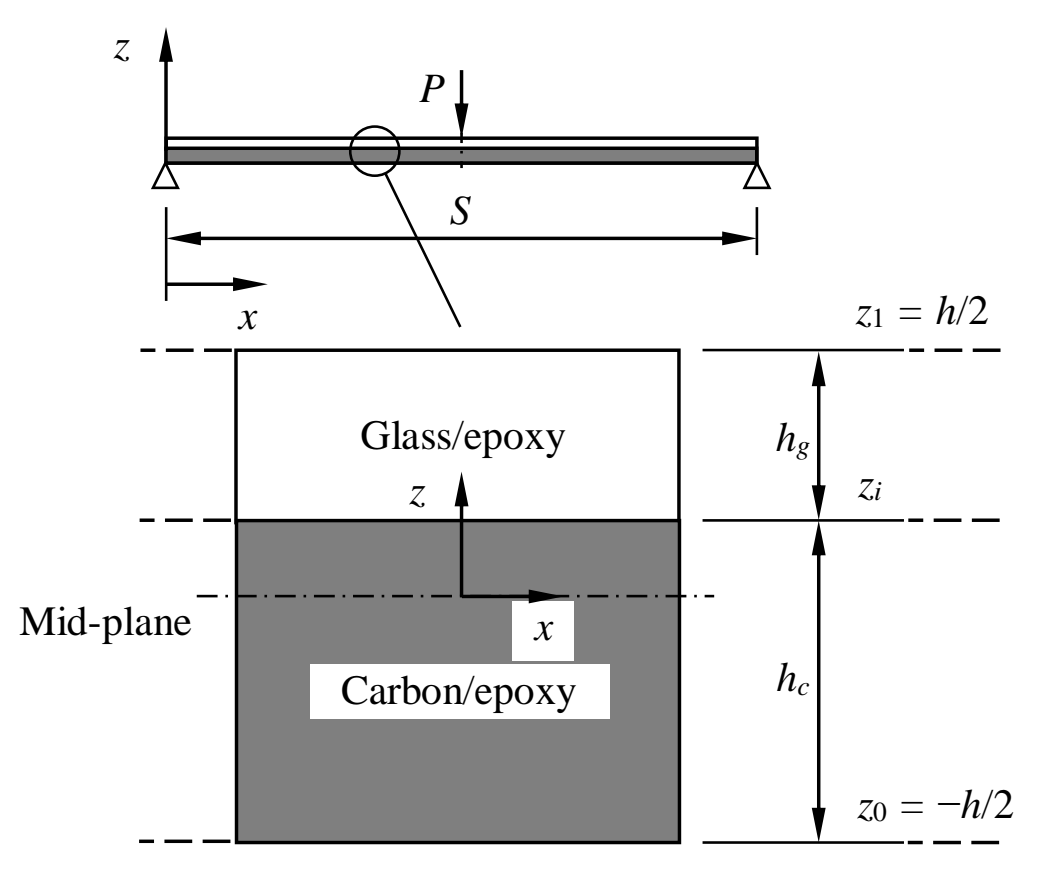

Figure 4: A hybrid composite specimen under the three point bending

Figure 5: An example finite element model

The stresses at both surfaces of each section are examined, and the applied load $P$ is increased until one of the stresses reaches the strength. The maximum load is then used for calculating the flexural strength

$$
S_{F}=\frac{3 P_{\max } S}{2 b h^{2}}
$$

It should be noted that Eqn. 9 gives an apparent flexural strength based on the assumption of linear stress distribution along the thickness, which reflects the maximum load a specimen can withstand given the span and depth.

The flexural strength of the hybrid composites using the RoM is given by

$$
S_{F R o M}=S_{F c}\left(1-r_{h}\right)+S_{F g} r_{h}
$$


The hybrid effect is given by

$$
e_{h}=\frac{S_{F}}{S_{F R o M}}-1
$$

\section{Results}

The fibre volume fractions of carbon/epoxy and glass/epoxy plies are chosen to be $40 \%$ and $60 \%$, respectively, so that the full carbon/epoxy and full glass/epoxy composites have approximately equal flexural strengths. Four hybrid composites: T700S\&S-2, T700S\&E, P-100\&S-2, and P$100 \& E$ are studied. For each hybrid composite, the flexural strengths are obtained from FEA by using three compressive failure models: Lo-Chim, Budiansky and the shear models, respectively.

The flexural strengths of the T700S\&S-2 fibre reinforced epoxy hybrid composite at various hybrid ratios are shown in Figure 6. It is seen that Lo-Chim and Budiansky models produce very similar results, while the shear model gives much lower flexural strength. The flexural strength predicted by the shear model is $14 \%$ lower compared to that predicted by Lo-Chim model. For all three models, positive hybrid effects are obtained by partial substitution of carbon fibres for glass fibres in T700S carbon fibre reinforced composites [7].

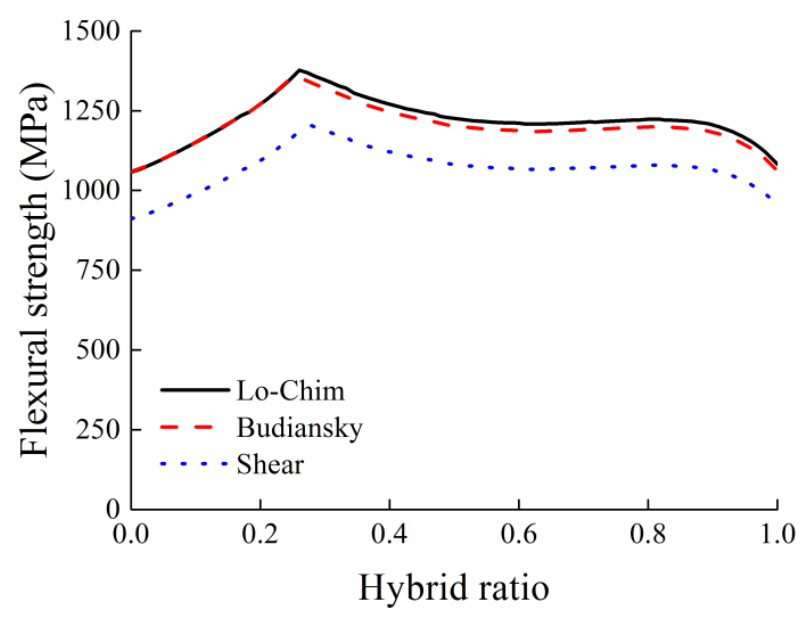

Figure 6: Flexural strengths of various modes for T700S carbon \& S-2 glass/epoxy hybrid composites when the fibre volume fractions for carbon/epoxy and glass/epoxy sections are $40 \%$ and 60 , respectively 
The flexural strengths of the P-100\&S-2 fibre reinforced epoxy hybrid composite at various hybrid ratios are shown in Figure 7. It is also seen that Lo-Chim and Budiansky models produce very similar results for all hybrid ratios. At low hybrid ratios, the shear model predicts significantly lower flexural strength, since shear failure is usually associated with lower flexural strength. The failure mode is shear compression. For example, the flexural strength of the full carbon/epoxy composite predicted by the shear model is $17 \%$ lower than those predicted by the other two models. When the hybrid ratio increases, the composite fails in tension, and all three failure models predict the same flexural strength. When the hybrid composite approaches the full glass composite, since P-100 fibres have much lower strain-to-failure, the load is carried by the S-2 glass fibre composite, and thus the failure mode switches to compression.

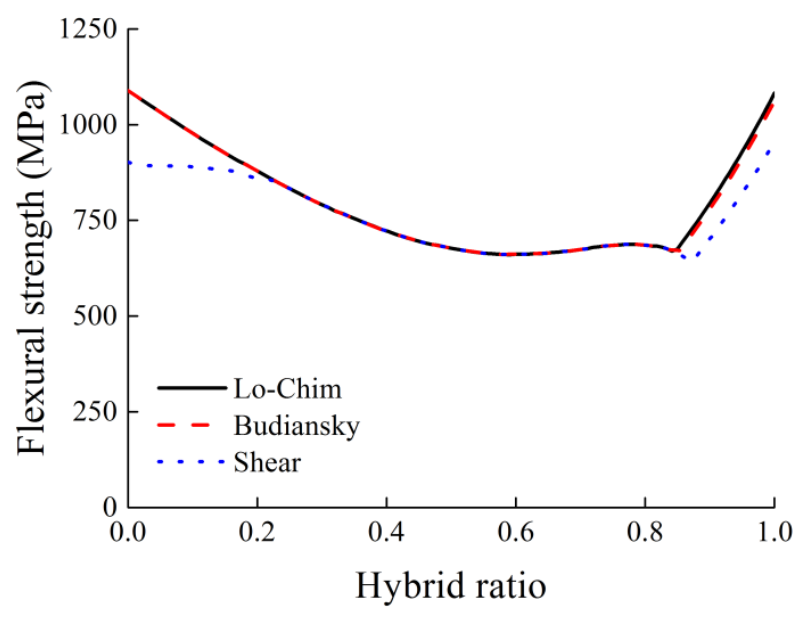

Figure 7: Flexural strengths of various modes for P-100 carbon \& S-2 glass/epoxy hybrid composites when the fibre volume fractions for carbon/epoxy and glass/epoxy sections are $40 \%$ and 60 , respectively

If the fibre volume fractions of carbon/epoxy and glass/epoxy plies are chosen to be both $50 \%$, the flexural strengths of the T700S\&S-2 fibre reinforced epoxy hybrid composite at various hybrid ratios are shown in Figure 8. It is seen that at low hybrid ratio, the shear model predicts significant lower flexural strength than Lo-Chim or Budiansky model. At low hybrid ratios, the flexural strength predicted by the shear model is $27 \%$ lower compared to that predicted by Lo-Chim model. 


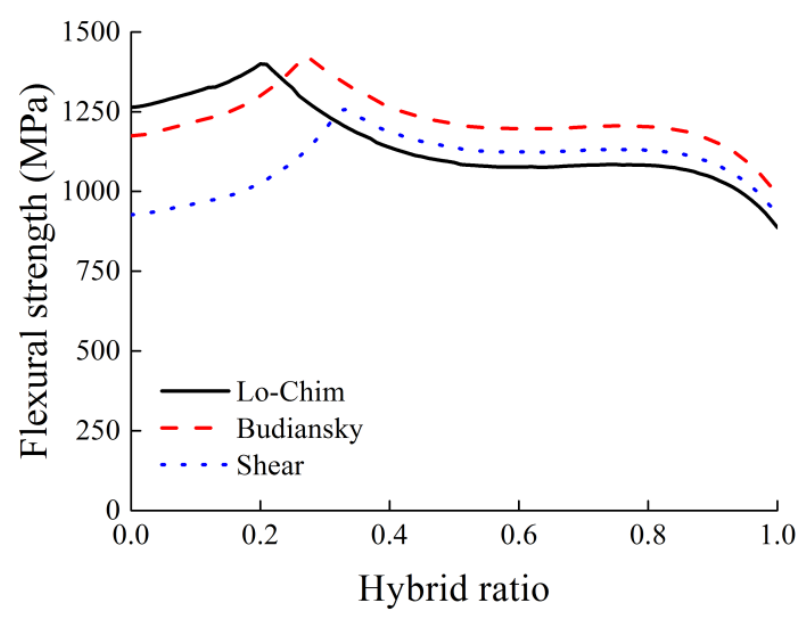

Figure 8: Flexural strengths of various modes for T700S carbon \& S-2 glass/epoxy hybrid composites when the fibre volume fractions for carbon/epoxy and glass/epoxy sections are both $\mathbf{5 0 \%}$

The flexural strengths of the P-100\&S-2 fibre reinforced epoxy hybrid composite at various hybrid ratios are shown in Figure 9. Compared to as shown in Figure 7, similar trends are found. When the hybrid ratio is greater than 0.4 , all three failure models predict very similar results, and failure is dominated by tension failure of the carbon/epoxy section, except when approaching to the full glass composites. When the hybrid ratio is less than 0.4 , the shear model predicts significantly lower flexural strength, which is associated with the shear compression failure mode, while the other two failure models predict tension failure of the carbon/epoxy section. The flexural strength due to shear failure can be $30 \%$ lower than that due to tension failure. For full carbon/epoxy composites, however, all three failure models predict failure due to compression. The flexural strength due to shear failure is $32 \%$ lower than those predicted by Lo-Chim or Budiansky model. 


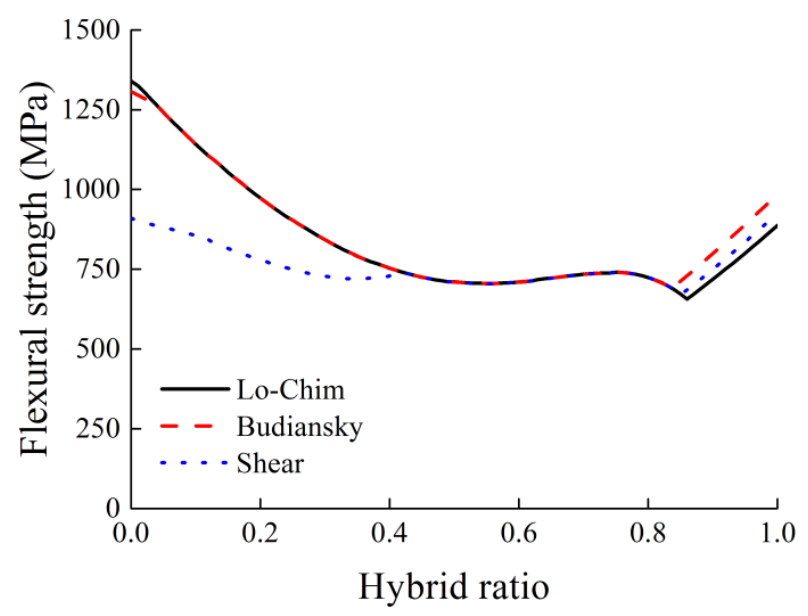

Figure 9: Flexural strengths of various modes for $\mathrm{P}-100$ carbon \& $\mathrm{S}-2$ glass/epoxy hybrid composites when the fibre volume fractions for carbon/epoxy and glass/epoxy sections are both $\mathbf{5 0 \%}$

The flexural strengths of the T700S\&S-2 fibre reinforced epoxy hybrid composite from our previous experimental study are compared with the predictions by three compressive failure models: Lo-Chim, Budiansky and the shear models. Four stacking sequences: $[0]_{6 \mathrm{C}},\left[00_{\mathrm{G}} / 0_{4 \mathrm{C}}\right]$, $\left[0_{2 \mathrm{G}} / 0_{3 \mathrm{C}}\right]$ and $[0]_{5 \mathrm{G}}$ are investigated. The results are shown in Figure 10. It is seen that the shear model gives lower flexural strength than Lo-Chim or Budiansky model at low hybrid ratios. This suggests shear failure is more likely to occur for $[0]_{6 \mathrm{C}}$ and $\left[0_{\mathrm{G}} / 0_{4 \mathrm{C}}\right]$. This is in good agreement with our experimental results [7]. Shear failure for $[0]_{6 \mathrm{C}}$ and $\left[0_{\mathrm{G}} / 0_{4 \mathrm{C}}\right]$ is evident. The lower flexural strength and modulus values are mainly due to shear failure. For $\left[0_{2 \mathrm{G}} / 0_{3 \mathrm{C}}\right]$ and $[0]_{5 \mathrm{G}}$, the dominant failure mode is microbuckling, which is in good agreement with Lo-Chim model prediction.

FEA gives $12 \%$ strength variation for $[0]_{6 \mathrm{C}}$ and $\left[0_{\mathrm{G}} / 0_{4 \mathrm{C}}\right]$ stacking configurations, and $8 \%$ for $\left[0_{2 \mathrm{G}} / 0_{3 \mathrm{C}}\right]$ and $[0]_{5 \mathrm{G}}$ configurations. For comparison, the experiments give higher variations between $11 \%$ and $29 \%$. 


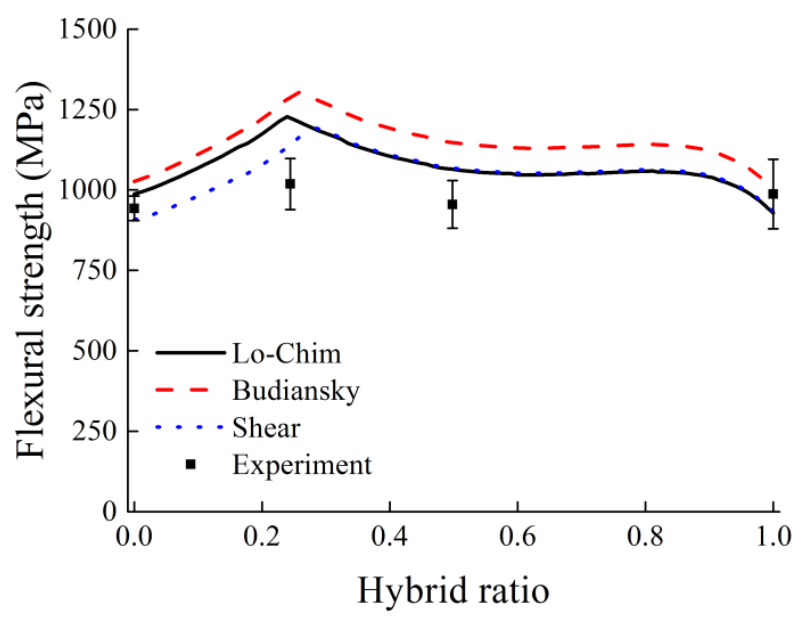

Figure 10: Comparison of flexural strengths for T700S carbon \& S-2 glass/epoxy hybrid composites from experiments and model predictions

\section{Conclusions}

The flexural behaviours of the of glass and carbon fibre reinforced epoxy hybrid composites made from two types of glass fibres, S-2 and E, and two types of carbon fibres, T700S and P-100 are presented in this paper. The flexural properties are computed using an approach based on FEA. It is shown that partial substitution of carbon fibres for glass fibres in high strength carbon fibre (e.g. T700S) reinforced composites improves the flexural strength, but partial substitution of carbon fibres for glass fibres in high modulus carbon fibre (e.g. P-100) reinforced composites does not improve the flexural strength.

Three compressive strength models are used for predicting the flexural strength. It is shown when shear failure occurs, the flexural strength is $20-30 \%$ lower compared to other failure modes. This can partially explain the uncertainties of the flexural strength.

\section{References}

[1] Dong C, Davies IJ. Optimal design for the flexural behaviour of glass and carbon fibre reinforced polymer hybrid composites. Materials \& Design. 2012;37:450-7.

[2] Dong C, Davies IJ. Flexural properties of glass and carbon fiber reinforced epoxy hybrid composites. Proceedings of the Institution of Mechanical Engineers, Part L: Journal of Materials Design and Applications. 2013;227(4):308-17. 
[3] Dong C, Davies IJ. Flexural properties of E glass and TR50S carbon fiber reinforced epoxy hybrid composites. Journal of Materials Engineering and Performance. 2013;22(1):41-9.

[4] Dong C, Davies IJ. Flexural and tensile strengths of unidirectional hybrid epoxy composites reinforced by S-2 glass and T700S carbon fibres. Materials \& Design. 2014;54:955-66.

[5] Dong C, Davies IJ. Flexural and tensile moduli of unidirectional hybrid epoxy composites reinforced by S-2 glass and T700S carbon fibres. Materials \& Design. 2014;54:893-9.

[6] Dong C, Duong J, Davies IJ. Flexural properties of S-2 glass and TR30S carbon fiber-reinforced epoxy hybrid composites. Polymer Composites. 2012;33(5):773-81.

[7] Dong C, Ranaweera-Jayawardena HA, Davies IJ. Flexural properties of hybrid composites reinforced by S-2 glass and T700S carbon fibres. Composites Part B: Engineering. 2012;43(2):57381.

[8] Isa MT, Ahmed AS, Aderemi BO, Taib RM, Mohammed-Dabo IA. Effect of fiber type and combinations on the mechanical, physical and thermal stability properties of polyester hybrid composites. Composites Part B: Engineering. 2013;52:217-23.

[9] Song JH. Pairing effect and tensile properties of laminated high-performance hybrid composites prepared using carbon/glass and carbon/aramid fibers. Composites Part B: Engineering.

2015;79:61-6.

[10] Tekalur SA, Shivakumar K, Shukla A. Mechanical behavior and damage evolution in E-glass

vinyl ester and carbon composites subjected to static and blast loads. Composites Part B:

Engineering. 2008;39(1):57-65.

[11] Wonderly C, Grenestedt J, Fernlund G, Cepus E. Comparison of mechanical properties of glass fiber/vinyl ester and carbon fiber/vinyl ester composites. Composites Part B: Engineering. 2005;36(5):417-26.

[12] Marom G, Fischer S, Tuler FR, Wagner HD. Hybrid effects in composites: conditions for positive or negative effects versus rule-of-mixtures behaviour. Journal of Materials Science. 1978;13(7):1419-26.

[13] Subagia IA, Kim Y, Tijing LD, Kim CS, Shon HK. Effect of stacking sequence on the flexural properties of hybrid composites reinforced with carbon and basalt fibers. Composites Part B:

Engineering. 2014;58:251-8.

[14] Atiqah A, Maleque M, Jawaid M, Iqbal M. Development of kenaf-glass reinforced unsaturated polyester hybrid composite for structural applications. Composites Part B: Engineering.

2014;56:68-73.

[15] Venkateshwaran N, Elayaperumal A, Sathiya G. Prediction of tensile properties of hybridnatural fiber composites. Composites Part B: Engineering. 2012;43(2):793-6.

[16] Boopalan M, Niranjanaa M, Umapathy M. Study on the mechanical properties and thermal properties of jute and banana fiber reinforced epoxy hybrid composites. Composites Part B:

Engineering. 2013;51:54-7.

[17] Chou T-W. Microstructural Design of Fiber Composites. Cambridge, U.K.: Cambridge University Press; 1992.

[18] Chamis CC, Handler LM, Manderscheid JM. Composite Nanomechanics: A Mechanistic Properties Prediction. NASA/TM-2007-214673; 2007.

[19] Lo KH, Chim ESM. Compressive strength of unidirectional composites. Journal of Reinforced Plastics and Composites. 1992;11(8):838-96.

[20] Budiansky B, Fleck NA. Compressive failure of fibre composites. Journal of the Mechanics and Physics of Solids. 1993;41(1):183-211.

[21] Zhang G, Karger-Kocsis J, Zou J. Synergetic effect of carbon nanofibers and short carbon fibers on the mechanical and fracture properties of epoxy resin. Carbon. 2010;48(15):4289-300. 